Rizk, R., Sobh, D., Abou Yassin, A., Hamzeh, F. (2018). "Studying the mindset of corruption in the construction industry- A Lean Perspective." In: Proc. 26th Annual Conference of the International. Group for Lean Construction (IGLC), González, V.A. (ed.), Chennai, India, pp. 316-325. DOI: doi.org/10.24928/2018/0282. Available at: www.iglc.net.

\title{
STUDYING THE MINDSET OF CORRUPTION IN THE CONSTRUCTION INDUSTRY- A LEAN PERSPECTIVE
}

\author{
Ruba Rizk ${ }^{1}$, Dana Sobh ${ }^{2}$, Abd Allah Abou Yassin ${ }^{3}$, Farook Hamzeh ${ }^{4}$
}

\begin{abstract}
Studies have shown that the construction industry practice involves corruption. Several factors such as the complexity of the project and organizations involved coupled with scarce sanctions on corrupt activities are basic hurdles for reducing corruption. Lebanon's construction industry is no exception since it is one of the developing countries that lack anti-corruption processes. The aim of this study is to (1) investigate the mindset behind unethical behavior in construction that has detrimental effects on the community and (2) suggest lean-based frameworks that can impact processes and behavior to reduce corruption. Surveys were conducted to better assess the level of awareness of the Lebanese community with regards to corruption, identify existing mitigation methods, and evaluate the importance and feasibility of integrating lean culture into the construction industry. Respondents do not consider some basic corrupt actions to be a serious problem indicating that there is a need for more efforts to raise the community's awareness to the significance of fighting corruption. An anti-corruption framework was designed using lean principles and tools was suggested to better mitigate and control corrupt acts in the Lebanese construction industry. Results show that the construction industry seems ready to accommodate this change. Nevertheless, it must happen at a low pace.
\end{abstract}

\section{KEYWORDS}

Corruption, Lean, Lebanon, Bribery, Anti-Corruption Tools, Integrity.

\section{INTRODUCTION}

Corruption is defined by Transparency International as "the abuse of entrusted power for private gain". The construction industry is known worldwide for corruption. According to

1 Masters Student, Civil and Environmental Engineering Dept., American University of Beirut, Lebanon, +961 71283 626, rmr24@mail.aub.edu

2 Masters Student, Industrial Engineering. Dept., American University of Beirut, Lebanon, +961 71537 981,dns12@mail.aub.edu

3 Masters Student, Civil and Environmental Engineering Dept., American University of Beirut, Lebanon, +9613043626, awa19@mail.aub.edu

4 Assistant Professor, Civil and Environmental Engineering Dept., American University of Beirut, Lebanon,+961 70680 523, fh35@aub.edu.lb 
the Bribe Payers Index in 2011, the amount of corruption in construction surpasses any other sector in the economy (Transparency International, International Secretariat, 2011). Corruption prevails in the construction sector due to many reasons. Specifically, the large funds going into these projects aid in price inflation and hiding huge bribes. The global construction market is estimated to be worth $\$ 3,200$ billion per year. However, it is stated by the American Society of Civil Engineers that $\$ 340$ billion per year of construction cost worldwide is accounted for corruption (Sohail \& Cavill, 2008). To understand the logic behind these findings, this paper aims at analyzing the mindset of people primarily responsible for the mentioned numbers and propose some lean tools and principles that may promote the reduction of corruption in the construction industry while taking Lebanon as a case study.

\section{CORRUPTION FORMS, CAUSES AND IMPLICATIONS}

From literature, many forms of corruption were identified, some of them are major, and others are collateral. Le et al. (2014) identified many forms of corruption mainly: 1) Nepotism which can take the form of political pressure or abuse of power, 2) Bribery as taking either cash payment or non-monetary advantages for unjustifiable reasons, 3) Extortion taking the form of physical or financial threats, and many more forms such as fraud, embezzlement, bid rigging, negligence, conflict of interest, kickback, unfair conduct, dishonesty, and front companies.

Corruption in construction has multiple causes including: intense competition in the tendering process, lack of transparency in the selection criteria for tenderers, inappropriate political interferences in cost decisions, insufficient sanctions, complexity of institutional roles and functions, complexity of the project itself, weak transcription of records, asymmetric information among project parties, and relatively low ethical standards (Le et al. 2014; Tanzi 1998; Bologna \& Nord 2010; Dorée 2004; Sohail \& Cavill, 2008). Furthermore, the culture of each country plays a major role in advocating corrupt practices where gift-giving is mistaken for bribery (Luo, 2004). Culture also influences one's tendency to carry out corrupt actions so, according to Nordin et al. (2013) who interviewed Malaysian construction practitioners over the matter of corruption, it is safe to assume that such unethical acts are, at least partially, due to human behavior.

In relation to the construction industry and the public at large, these unethical practices result in destructive fallouts with respect to the quality of the built facility, project delivery duration, increasing competition among stakeholders and project prices, criminal prosecution and fines, and much more (Sohail \& Cavill, 2006; Murray \& Meghji, 2009; Stansbury, 2005). In addition, corruption reduces building lifespan and increases building collapse rates and death toll rates (Lewis, 2003; Ambraseys, 2010). Reports released by OECD (2014) state that corruption is approximated to account for $\$ 2.6$ trillion dollars annually, which is $5 \%$ of the global gross domestic product (GDP), where around $\$ 1$ trillion is in the form of bribery. Moreover, as stated by Kenny (2009), the construction industry is worth $\$ 1.7$ trillion on an international level which constitutes 5\%$7 \%$ of most countries' GDP. Since the greater number of corruption incidents occur in the 
construction field, it is important to constantly look for innovative measures to prevent global and local harm.

\section{STATUS IN LEBANON}

Even though corruption has always existed in Lebanon, its effects increased after the end of the civil war in 1990. Corruption in Lebanon occurs in all its forms including nepotism, patronage, bribery, embezzlement, vote-buying and many other forms (Lebanese Transparency Association, 2011). However, political corruption has been identified as Lebanon's the most serious corruption challenge. This is reinforced by the opinion of the Lebanese citizens about corruption. According to the Transparency International's Global Corruption Barometer 2011, 82\% of the surveyed participants acknowledged that corruption has increased in the last 3 years. Moreover, $71 \%$ of the participants considered the government's actions against corruption as inefficient, or neither efficient nor inefficient. In addition, $68 \%$ of the survey participants did not trust the government as a credible actor in the fight against corruption (Wickberg, 2012).

According to the 2015 Open Budget Index Survey that was produced by the International Budget Partnership (IBP), Lebanon scored 2 out of 100 in transparency; which is substantially lower than the global average score of 45 . Thus, Lebanon is categorized as one of the countries that provide least minimal information.

According to the 2009 Global Integrity Index, Lebanon scored 53 out of 100 and is recognized as a "very weak" country in terms of integrity. (Global Integrity, 2009) The low score is due to the absence of anti-corruption legislation and lack of institutions such as Ombudsman. (Lebanese Transparency Association, 2011)

The three major forms of corruption in Lebanon are: political, bureaucratic, and bribery. The sectors most affected by corruption show to be the most crucial sectors and that if corrupted, would affect all other sectors beneath. These sectors are the political parties, public administration, police, parliament and even judiciary (Wickberg, 2012).

When it comes to the Lebanese construction industry, around $50 \%$ of the construction firms are expected to "give gifts" to obtain construction permits, and around $20 \%$ of the firms do the same for operating license or labor inspection (Kenny, 2009). Moreover, from the owner's perspective, government bureaucracy and corruption in Lebanon are major contributors to the delay of construction project due to their negative effect on project financing (Mezher, Tawil, 1998).

Stifi et al. (2017) defined corruption as core waste that is characterized by producing other types of waste in addition to its own waste. Three main reasons for corruption in construction were also identified: lack of integrity, lack of transparency, and lack of accountability (Stifi et al., 2017). The objective of this research is to study construction professionals' perspective on unethical behavior and suggest lean-based frameworks that can impact processes and behavior to reduce corruption. There is very limited literature covering this subject in Lebanon, making this paper the first to address the issue which is critical for improving the industry. 


\section{RESEARCH METHODOLOGY}

To better understand the topic at hand, the authors looked at previous contributions on corruption in the construction field. A survey was developed based on a previously designed questionnaire by The Chartered Institute of Building (Tanzi, 1998). It was modified to fit the Lebanese environment and construction industry. The general structure of the survey consists of two parts; demographic related questions as well as questions related to perception towards unethical behavior and the frequency of it happening. The survey included two matrix questions which were recorded in the 4 point Likert Scale to ensure accurate mapping (Marsden \& Wright, 2010). Pilot testing was done randomly to make sure the proposed questions are clear and the results were effective.

\section{SAMPLING, RESPONDENT PROFILE, AND ETHICS}

Purposive non-probability critical sampling has been done in this study based on the researchers' knowledge of the population and the purpose of the study. Also, snowball sampling was used to fasten the process of finding eligible participants, as suggested by Wilson (2014). Characteristics of participants in the quantitative method include: Lebanese, holder of a Bachelor's degree, and working in the construction industry. Ethical issues regarding a participants' protection and confidentiality was insured by not including any personal identifiers. An informed consent was handled at the beginning of the survey and participants were mindful that they could quit from the study at any time. The research was submitted to an institutional review board to ensure the safety and welfare of the participants.

\section{INSTRUMENTS, DATA SIZES, AND DATA ANALYSIS}

An online cross-sectional survey was selected to facilitate the process of sharing to respondents in remote places. The survey included 17 questions (close and open-ended). A link for the survey was disseminated through email and social media. The final sample size was 35 survey respondents (Lebanese 100\%, Males 80\%). Out of 36 surveys, 1 was discarded due to abandonment. The quantitative data was statistically analyzed and represented as descriptive statistics.

\section{JUSTIFICATION OF METHODS}

A cross-sectional unstructured survey is selected for this study since the objective is to collect large amounts of data to understand which factors are behind corruption in construction in Lebanon as well as to understand how unethical management practices are perceived.

\section{RESULTS AND DISCUSSION}

\section{RESPONDENT PROFILE}

The respondents were all Lebanese, from different age groups (23 - 39), and coming from different work sectors (51.4\%onsite construction, 28.6\%architecture engineering and design, $17.1 \%$ construction management consultant, and $2.9 \%$ academics and universities) 
with males forming $80.6 \%$ of the respondents. Work experience was distributed as followed: $77.8 \%<5$ years, $16.7 \%$ with $6-10$ years, and $5.6 \%$ with $11+$ years.

\section{FINDINGS}

When asked about their perception of how common unethical behavior in the Lebanese construction industry is, $44.4 \%$ answered fairly common, 38.9\% answered extremely common, and $16.7 \%$ answered that it was not common. With $0 \%$ saying that it wasn't common at all.

Results also showed that $63.9 \%$ have previously uncovered unethical behavior in management practices during regular checkups/auditing, $13.9 \%$ by chance, $8.3 \%$ tip off, and $2.8 \%$ using Building Information Modelling (BIM).

Figure 1 shows the percentage of participants who believe that the mentioned unethical behaviors form a serious problem, in relation to the construction industry. For example, almost $40 \%$ of the surveyed participants answered that they find the act of leaking information to a preferential bidder to be a serious problem. It is also interesting to indicate that only $20 \%$ of the respondents stated that including false extra cost to a contract claim is a serious problem.

Also referring to figure 1 , one can identify at least 5 unethical actions characterized by having $30-35 \%$ of their answer that these corrupt actions are considered to be minor problems. Looking at such statistics, where a low percentage of the respondents believe corrupt behavior is a serious problem and a substantial percentage refer to these same activities as minor problems, it can be concluded that there is a lack of awareness about the severe damage caused by these prevalent wrongdoings. The authors were able to identify two main reasons as to why the Lebanese are not aware of the crisis they are in. Practitioners say that corruption is highly common and on all levels is due to the unethical practices and poor contractual setup that allows for dishonest behavior.

Another item in the survey aimed to examine at what level the respondent thinks unethical behavior in management practices are most likely to occur. Options included: individual at operational level, individual at middle management level, individual at senior management level, corporate at operational level, corporate at middle management level, corporate at senior management level, client, local government, national government. The answers varied and basically covered all of the alternatives which indicates that really corruption in Lebanon may occur at any and every level.

\section{DISCUSSIONS}

The industry is structured in an adversarial and myopic manner that leads individuals and corporations to deprive others and possibly commit illegal actions in order to get their bigger share of the pie. The above-mentioned reasons are also a result of the weak educational anticorruption campaigns on all levels (childhood, school, college and job education) and the immature environment whereby you can find the same person working with a corporation in Lebanon behave differently than if they were working in a corporation in any other country.

The substantial amount of loses due to bad management practices sheds light on the importance of taking actions towards corruption. Moreover, the significant low 
percentages of participants who believe that the Lebanese construction industry or the government are battling corruption indicate the need for implementing innovative techniques in order to alter the way corporation and the government function in opposition to corruption. This study proposes lean principles and tools as a methodology to mitigate unethical behaviour particularly in institutions that work in relation to the Lebanese construction industry.

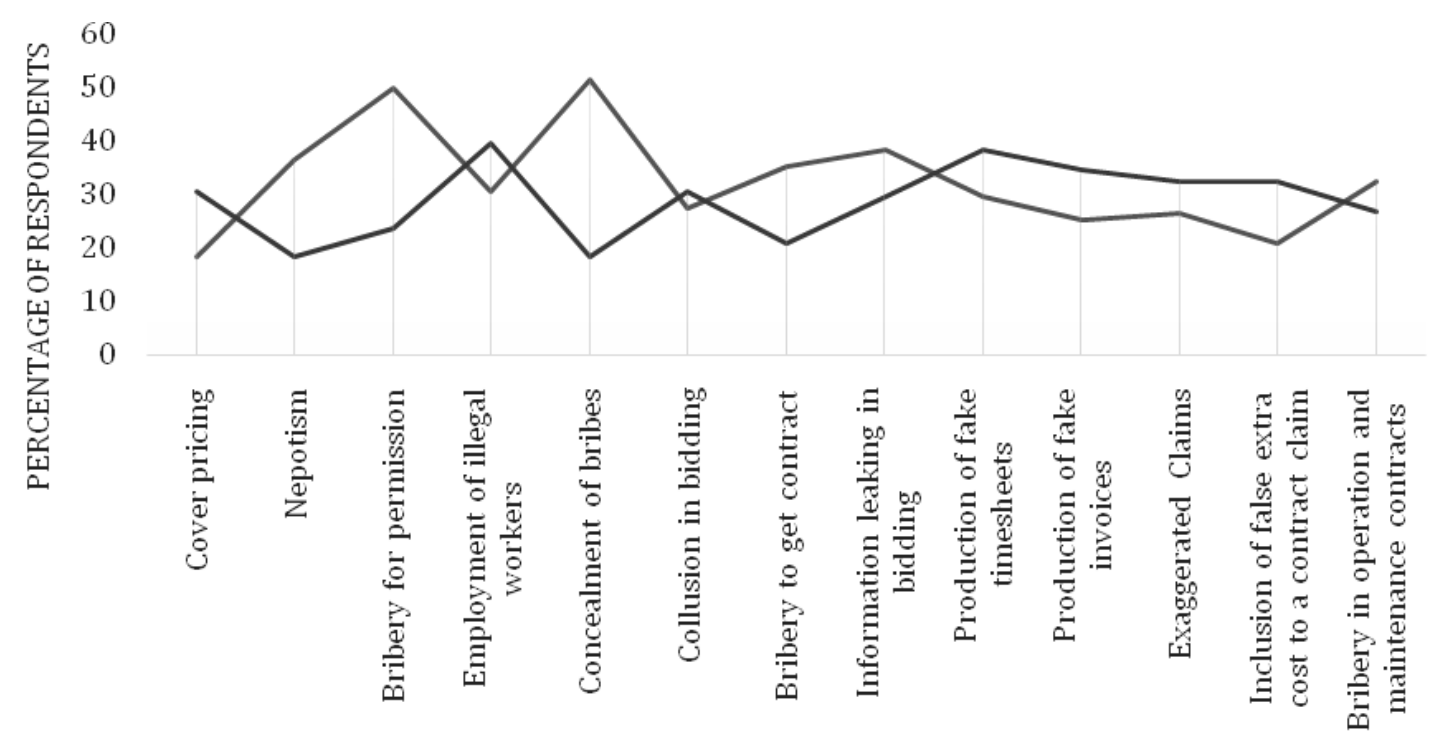

FORMS OF CORRUPTION

- Major Problem -Minor Problem

Figure 1: Extent of Corruption

\section{LEAN FRAMEWORK TO ELIMINATE CORRUPTION}

From literature, it is prevalent that corruption in Lebanon is prevalent at all levels of the country, starting from governmental officials down to clerks in regulatory offices. A problem that is epidemic and deep rooted needs to be analysed from the systemic level down to the individual level. Although corrupt acts are linked, the study separates corruption in the Lebanese government from corruption in the Lebanese construction industry to address each issue properly.

Using the 14 lean principles of Toyota (Liker, 2004) and lean tools such as Last Planner System, Building Information Modelling and Value Stream Mapping, a framework for eliminating corruption will be introduced.

\section{ANTI-CORRUPTION FRAMEWORK FOR GOVERNMENTAL PRACTICES}

The main reason for the wide spread of corruption in Lebanon is nepotism, and to eliminate nepotism, a country wide awareness campaign should be launched showing citizens how much would corruption cost them based on detailed studies. Public awareness is vital in case of Lebanon since it is a democratic country and the politicians 
are selected based on voting. This would start by nominating parliament members that are fully aware of the impact of corruption on the country and its citizens and have high ethics. When ethical parliament members are present in the government, they can start following lean principles starting by basing management decisions on long term goals. The latter can be translated to action if an anti-corruption strategy is planned. At the core concepts of this strategy should be accountability, integrity and transparency.

The second lean principle states that the right process will produce the right results. The current bureaucratic and hierarchical procedure to get any official documents from governmental offices is a daunting procedure. If change is to happen, the process should be optimized to give short cycle times with high quality. Autonomation using reliable technology would also reduce human intervention hence reduce the possibility of corrupt decisions. One thoroughly tested technology used internationally is e-governance. Egovernance is the process of digitization of data used for providing services by governmental agencies. This digitization reduces interaction between humans, and in the process hinders the dissemination of corruption (Andersen, 2009).

Although the Lebanese government has launched an e-governance strategy in 2008 with an expected end date of 2015, it wasn't fully implemented, and no action was taken since 2013 (e-gov, 2013).

Next step in our lean framework is developing people. This can be achieved by paying employees a salary that would ensure they can have a good quality of living. When employees are satisfied with their jobs, they will not look for illegal ways to make more money. This would pave the way for developing a culture that supports anticorruption.

The last step is to develop and control this framework. This can be achieved by setting and measuring key performance indicators (KPIs) that would monitor performance. These KPIs can be used to assess the current state and continuously develop the framework.

However, it will be challenging to incorporate lean principles into governmental organizations. Even though they are the ones who deal with the publics' money and hence should be extra careful about it, this is not always the case. It requires being proactive and not myopic, so it might not be easy to convince officials with such concepts.

\section{ANTI-CORRUPTION TOOLS FOR THE CONSTRUCTION INDUSTRY}

Ohno's famous statement mentions: "Lower the river to reveal the rocks" (Liker, 2004). This is why organizations should be proactive about mitigating corruption. It would be easier to implement lean principles and tools in the privatized sector because they have better control over time and they are profit driven, so every dollar counts. Companies can start by using the toolkits compiled below to deliberately reduce the level of corruption that exists in their projects.

\section{Last Planner System (LPS)}

Lean construction requires integrity and corruption poses a lack of integrity. Integrity can play a vital role in changing a corruptive "culture"through striving for reliable promises. According to Erhard et al. (2013), engineers and stakeholders in the construction industry wonder about reasons for projects failure yet never seem to consider lack of integrity as a 
plausible explanation. The same authors then introduced in their work a model for integrity, referred to as "honouring one's word". The "one's word" in Erhard's model of integrity is equal to "promise" in the LPS; therefore, LPS can be considered as a transplantation of integrity into the construction industry. Based on the above, integrity should also reduce corruption. Awareness about the LPS has started to appear in Lebanon (Hamzeh et al., 2016), but more implementations are needed.

\section{Building Information Modelling (BIM)}

BIM as described by Janssen et al. (2017) is a complete and differentiated information system, capable of influencing the project design and execution cycle, as well as allowing greater technical and social control over public spending. Janssen et al. (2017) argue that if BIM was adopted on a country level and is responsible for all interactions between people and the exchange of information leading to building and operating publically funded buildings, the common data environment within BIM would be the single source of truth that adds more transparency and accountability, as well as social control over the whole process.

The need for transparency shows how BIM is a necessary tool to prevent and control corruption in the construction industry, not only on the project level, but at the level of a global complex system. Benefits of BIM however, will not be exploited unless the adoption is mandated by the government and becomes a legal requirement for publicly funded projects where corruption is most prevalent.

\section{Value Stream Mapping (VSM)}

Value stream mapping (VSM), allows us to analyse the process by developing a map of the initial state. When implemented, an improved state map is established and used to optimize the system (Hines \&Taylor, 2000). VSM increases process transparency and enables everyone concerned to understand the status of the system. Increased transparency is necessary for continuous process improvement (Womack \&Jones, 2003). By using the VSM technique to document all the value and non-value adding activities required to finish a construction project would make it clear to pinpoint where the waste is occurring. Construction companies would start by identifying what waste is being caused by corruption in their organizations internally and then grow and expand to include other stakeholders in their value stream map. By identifying what is the waste found in their system, they can better implement strategies to mitigate it.

\section{STUDY LIMITATIONS}

When it comes to the methodology, it is acknowledged that the study had limitations. The sample used was limited in size due to limited access to professionals in the field.

Some obstructions that one may face when opting to implement lean principles and tools are the classic problems such as resistance to change and not seeing the added value of the process. Some may have misconceptions as to what lean methodologies stand for and that it may require substantial effort to reach beneficial results. Moreover, culture is a huge barrier to implementing lean. According to one of the respondents, unethical behaviour is considered to be the norm in the Lebanese construction industry and part of the process to be able to move forward with the work; unlike other countries where it is 
hid better and is not as out in the open as it is here. Tools would create tremendous improvement in effective minimization of corruption, but without the right culture, tools would be obsolete.

\section{CONCLUSIONS AND RECOMMENDATIONS}

Evidence from the conducted survey shows that first, construction project participants are insufficiently aware of all the unethical behaviour that may lead to corruption in such an industry. Second, their neutral perception, in some cases, towards such malpractices justifies the large number of losses in the construction sector. And third, their consistent belief that there is no vivid action plan that serves to reduce the corruption rate in Lebanon. Therefore, integrity, accountability, and transparency are among the key characteristics of the suggested tools needed to mitigate for corruption. The increased added value to seeing everything early on, capturing problems, and being proactive is essential to the practice of the construction industry without fraudulent acts. The tools are also crucial in terms of reducing waste and doing things in an optimal manner. It would be a step in the right direction. It would reduce the chances of errors and give less incentive for stakeholders to play games and tricks if things are clear from the start of the project. It brings increased visibility and effort in the right place. However, that requires having a concerted effort from all the stakeholders for developing accurate augmented design model. It is a matter of experimenting and starting with one tool at a time starting with simple metrics such a percent plan complete (PPC), tracking, waste minimization, concepts that practitioners and stakeholders can sense and appreciate that could lead to good results with minimal effort. More advanced concepts can be implemented at later stages to hopefully reach a lean Lebanese construction world free of corruption.

\section{REFERENCES}

Ambraseys, N. (2010). "A note on transparency and loss of life arising from earthquakes.” J. Seismolog. Earthquake Eng., 12(3), 83.

Andersen, T. B. (2009)." E-Government as an anti-corruption strategy". Information Economics and Policy, 21(3), 201-210. E-gov. 2013. News \& Events.

Bologna, R., and Del Nord, R. (2010). "Effects of the law reforming public works contracts on the Italian building process." Build. Res. Inform.,28(2), 109-118.

Dorée, A. G. (2004). "Collusion in the Dutch construction industry: An industrial organization perspective.” Build. Res. Inf., 32(2), 146-156.

Erhard, W.; Jensen, C. and Zaffron, S. (2013). "Integrity: A Positive Model that incorporates the Normative Phenomena of Morality, Ethics, and Legality."

Global Integrity. (2009). Global Integrity Report.

Hamzeh, F.R., Kallassy, J., Lahoud, M., and Azar, R. (2016). "The First Extensive Implementation of Lean and LPS in Lebanon: Results and Reflections." In: Proc. 24th Ann. Conf. of the Int'l. Group for Lean Construction, Boston, MA, USA, sect.6 pp. $33-42$

Hines, P., \& Taylor, D. (2000). "Going lean". Cardiff, UK: Lean Enterprise Research Centre Cardiff Business School, 3-43. 
International Budget Partnership. (2015). Open Budget Survey, Lebanon

Janssen, P., Loh, P., Raonic, A., \& Schnabel, M. A. (2017).” BIM AND PUBLIC ADMINISTRATION".

Kenny, C. (2009). Transport Construction, Corruption and Developing Countries. Transport Reviews, 29(1), 21-41.

Le, Y., Shan, M., Chan, A. P., and Hu, Y. (2014). "Overview of corruption research in construction.” J. Manage. Eng., 10.1061/(ASCE)ME.1943 -5479.0000300, 02514001.

Lewis, J. (2003). "Housing construction in earthquake-prone places: Perspectives, priorities and projections for development.” Aust. J. Emergency Manage., 18(2), 3544.

Liker, J. K. (2004). "The Toyota way: 14 management principles from the world's greatest manufacturer". New York: McGraw-Hill.

Luo, Y. (2004). An Organisational Perspective of Corruption. Management and Organisation Review, 119-154.

M. Sohail, \& Sue Cavill. (2008). Accountability to Prevent Corruption in Construction Projects. Journal of Construction Engineering and Management, 134(9), 729-738.

Marsden, P. V., \& Wright, J. D. (Eds.). (2010). Handbook of Survey Research (Second edition). Bingley: Emerald.

Mezher, T. M., \& Tawil, W. (1998). Causes of delays in the construction industry in Lebanon. Engineering, Construction and Architectural Management, 5(3), 252-260.

Nordin, R. M., Takim, R., \& Nawawi, A. H. (2013). Behavioural Factors of Corruption in the Construction Industry. Procedia - Social and Behavioral Sciences, 105, 64-74.

Stansbury, N. (2005). Exposing the Foundations of Corruption in Construction. United Kingdom: Transparency International.

Stifi, A., Gehbauer, F. \& Gentes, S. (2017), 'Lean Anti-Corruption Toolkit' In: 25th Annual Conference of the International Group for Lean Construction. Heraklion, Greece, 9-12 Jul 2017. pp 445-452

Tanzi, V. (1998). "Corruption around the world: Causes, consequences, scope, and cures." Staff Papers, 45(4), 559-594.The Chartered Institute of Building. (2006). Corruption in the UK Construction Industry.pdf.

Transparency International, International Secretariat (Ed.). (2011). Bribe Payers Index 2011. Berlin: Transparency International.

Wickberg, S. (2012). Overview of corruption and anti-corruption in Lebanon. Transparency International.

Wilson, V. (2014). Research Methods: Sampling. Evidence Based Library and Information Practice, 9(2), 45-47.

Womack, J. P., \& Jones, D. T. (2010). "Lean thinking: banish waste and create wealth in your corporation." Simon and Schuster. 